\title{
Anatomical Changes Linked Performance of Two Indigenous Medicinal Plants, Withania Somnifera Dunal and Coleus Forskohlii Briq. Exposed to Supplemental Ultraviolet-B Radiation
}

\author{
Swabha Takshak ${ }^{1}$ and Shashi Bhushan Agrawal ${ }^{1 *}$ \\ ${ }^{1}$ Laboratory of Air Pollution and Global Climate Change, Department of Botany, Banaras Hindu University, \\ Varanasi, India \\ Email: sbagrawal56@gmail.com
}

\begin{abstract}
Supplemental ultraviolet-B (s-UV-B) radiation $\left(\operatorname{ambient}+3.6 \mathrm{kJm}^{-2}\right.$ day $\left.^{-1}\right)$ was given to two medicinal plants Withania somnifera and Coleus forskohlii for $3 \mathrm{~h} \mathrm{day}^{-1}$ during the solar noon period. Changes at the anatomical level were studied in leaves and roots of the plants. Variations were observed in all s-UV-B treated plant-parts (except roots of $W$. somnifera). The changes included increased leaf thickness ( $W$. somnifera), enhanced accumulation of UV-B absorbing compounds in leaves of both plants and roots of C. forskohlii, and reduced thickness of cork- and cambial cell layers in $C$. forskohlii. Due to reduction in the number of oil bodies in cork cells, essential oil content of $C$. forskohlii also reduced. The results suggest that the test plants are capable of defending themselves (at least partially) against s-UV-B; further in-depth studies are required to derive more substantial results linking the cellular level changes to the overall plant performance.
\end{abstract}

Keywords: Anatomy, C. forskohlii, s-UV-B, W. somnifera.

\section{Introduction}

Withania somnifera (Solanaceae) and Coleus forskohlii (Lamiaceae) are two medicinal plants which have been used in India in Ayurvedic and indigenous medicinal systems for centuries [1,2]. Also known as Ashwagandha, $W$. somnifera is an erect, evergreen, tomentose shrub, propagated by seeds, and primarily harvested for its roots. The whole plant has various medicinal properties. Roots, leaves, as well as seeds of $W$. somnifera are of medicinal importance, being used as aphrodisiac-, hepato-protective, anti-inflammatory-, therapeutic-, and rejuvenating agents. They have been found useful in treating several neurological disorders (including Parkinson's disease), skin-, and eye diseases, paralysis, tumors, and mental disorders such as memory loss and even Alzheimer's disease [3,4]. Leaves are instrumental in treating fevers and tumors, while roots are used against rheumatism, nervous disorders, and as rejuvenating agents, besides possessing antimicrobial properties [3,4,5]. The medicinal properties of $W$. somnifera are largely attributed to the withanolides present in its roots. Withanolides are steroidal lactones with various pharmacological properties. For instance, withanolide A is immuno-modulatory while withaferin $\mathrm{A}$ is effective against cancer [6,7].

C. forskohlii is a perennial aromatic herb harvested for its essential oil which is rich in various pharmaceutical diterpenoids. The plant yields a labdane diterpenoid, forskolin, biosynthesized in the cork cells of the root [8]. A number of diseases have been known to be cured/ treated using forskolin and C. forskohlii extracts. These include increasingly widespread disorders such as diabetes, obesity, blood pressure, and depression, as well as relatively rare ones such as epilepsy, angina, psoriasis, cancer, and heart ailments. Roots are used for treating skin diseases in particular, while the leaves are effective as a condiment and against intestinal disorders $[9,10]$. The essential oil obtained from the plant is aromatic and used in food flavouring and perfumeries as well as an antimicrobial agent [11].

Stratospheric ozone layer depletion has caused increased amount of solar UV radiation reaching the Earth. In recent years, however, due to successful implementation of Montreal Protocol, the emission of ozone depleting substances has been controlled; consequently, ozone hole recovery is expected in the years to come [12]. However, recent studies have indicated that this recovery is likely to be hampered by 
changing climatic conditions, altered land-use patterns, and newly quantified CFCs $[13,14,15]$. Hence, till the complete recovery of the ozone layer to the pre-1980 levels, enhanced UV-B radiation is likely to remain a potent stress factor influencing all aspects of life on Earth including plants.

UV-B (280-320 nm) has been known to induce changes in various aspects of plants including anatomical changes [16]. A limited number of studies have focussed on the anatomical changes in plants due to UV-B and even less studies have addressed medicinal plants as the test material. Moreover, changes in the roots due to elevated UV-B levels are far less studied than the leaves, probably because the former are not directly exposed to sunlight. To the best of our knowledge, UV-B induced anatomical changes in the test medicinal plants $W$. somnifera and $C$. forskohlii have not been studied to date. The present study is an attempt at making preliminary investigations as to the effects of supplemental UV-B ( s-UV-B) on anatomical changes in leaves and roots of the test plants.

\section{$2 \quad$ Materials and Methods}

\subsection{Experimental Site and Meteorological Conditions}

The experimental studies were conducted in the Botanical Garden, Department of Botany, Banaras Hindu University, Varanasi. The experimental period stretched from end of March to mid-July 2012 ( $W$. somnifera), and end of October 2012 to mid-February 2013 (C. forskohlii). The meteorological observations during the experimental period(s) are given in Table 1.

Table 1. Meteorological data during the experimental period.

\begin{tabular}{|c|c|c|c|c|c|c|}
\hline $\begin{array}{l}\text { W. somnifera } \\
\text { (2012) }\end{array}$ & $\begin{array}{c}\text { Maximum } \\
\text { temperature }\left({ }^{\circ} \mathrm{C}\right)\end{array}$ & $\begin{array}{c}\text { Minimum } \\
\text { temperature } \\
\left({ }^{\circ} \mathrm{C}\right)\end{array}$ & $\begin{array}{c}\text { Maximum relative } \\
\text { humidity }(\%)\end{array}$ & $\begin{array}{c}\text { Minimum relative } \\
\text { humidity }(\%)\end{array}$ & $\begin{array}{c}\text { Total } \\
\text { rainfall } \\
(\mathrm{mm})\end{array}$ & $\begin{array}{c}\text { Total } \\
\text { sunshine } \\
(\mathrm{h})\end{array}$ \\
\hline March & 32.5 & 15.7 & 63.8 & 34.5 & 3.8 & 258.2 \\
\hline April & 38.7 & 22.3 & 56.4 & 33.3 & 17.0 & 282.6 \\
\hline May & 41.9 & 28.9 & 43.9 & 25.8 & 0.0 & 283.8 \\
\hline June & 41.5 & 28.7 & 54.1 & 37.7 & 97.4 & 180.4 \\
\hline July & 34.3 & 26.2 & 88.2 & 78.4 & 307.5 & 111.6 \\
\hline \multicolumn{7}{|l|}{$\begin{array}{l}\text { C. forskohlii } \\
(2012 / 2013)\end{array}$} \\
\hline October & 33.3 & 20.1 & 86.0 & 68.9 & 15.2 & 252.7 \\
\hline November & 28.8 & 13.2 & 86.6 & 69.4 & - & 207.1 \\
\hline December & 23.4 & 10.0 & 85.7 & 65.4 & - & 176.8 \\
\hline January & 22.0 & 7.6 & 92.4 & 58.9 & 0.4 & 189.2 \\
\hline February & 25.9 & 12.6 & 89.4 & 58.2 & 62.4 & 190.5 \\
\hline
\end{tabular}

\subsection{Plant Material and Planting Conditions}

One month old plants obtained from the nursery were transplanted in $1 \mathrm{~m} \times 1 \mathrm{~m}$ experimental plots in 3 rows with 4 plants in each row (making a total of 12 plants per plot) at equal distances. 3 plots with 12 plants each were prepared for control as well as s-UV-B treated plants. The plots of $W$. somnifera were supplemented with organic manure thrice during the experimental period at equal intervals. To the $C$. forskohlii plots, $\mathrm{N}$ (nitrogen as urea), $\mathrm{P}$ (phosphorus as $\mathrm{P}_{2} \mathrm{O}_{5}$ ), and $\mathrm{K}$ (potassium as $\mathrm{KO}_{2}$ ) were added in the recommended doses of 40,60, and $50 \mathrm{~kg} \mathrm{ha}^{-1}$ respectively. Basal dose was applied at the time of field preparation (half the dose of $\mathrm{N}$ and full dose of $\mathrm{P}$ and $\mathrm{K}$ ) while the remaining half dose of $\mathrm{N}$ was applied as top dressing at 30 days after transplantation (DAT) [11]. Plants were watered at regular intervals as per the requirement. 


\section{3 s-UV-B Treatment}

Supplemental UV-B (s-UV-B) was given to the plants using UV-B lamps (Q Panel UV-B 313 40W fluorescent lamps, Q panel Inc., Cleveland, OH, USA) once they were established in the field. The control plants received ambient UV-B dose of $9.6 \mathrm{~kJ} \mathrm{~m}^{-2}$ day ${ }^{-1}$ in case of $W$. somnifera and $5.8 \mathrm{~kJ} \mathrm{~m}^{-2}$ day $^{-}$ 1 in case of $C$. forskohlii. The treated plants were subjected to ambient $+3.6 \mathrm{~kJ} \mathrm{~m}^{-2} \mathrm{day}^{-1} \mathrm{UV}-\mathrm{B}$ as weighted by Caldwell [17] generalised plant action spectrum normalised at $300 \mathrm{~nm}$. Cellulose diacetate filters (0.13mm thick; Cadillac Plastic Co., Baltimore, USA), with transmission down to 280nm were used to wrap up the UV-B lamps. The filters were replaced each week due to their photodegradation by UV-B. The distance between the plant canopy and the UV-B lamps was kept constant $(30 \mathrm{~cm})$ throughout the experimental period. s-UV-B was provided to the plants for $3 \mathrm{~h}$ day $^{-1}$ (11:00 to 14:00) during the solar noon period. Ultraviolet intensity meter (Model UVP Inc. San Gabriel. CA, USA) was used to measure the UV-B irradiance at the top of the plant canopy while the reading were converted to biologically effective UV-B radiation $\left(U V-B_{B E}\right)$ using Spectro Power Meter (Model Scientech, Boulder, USA).

\subsection{Sample Collection and Tissue Preparation}

Healthy leaves and roots of similar age and dimensions were collected from control and s-UV-B treated plants at 100 DAT for $W$. somnifera and at 90 DAT for C. forskohlii. Hand-cut sections were prepared from the freshly collected tissues, and sections mounted on glass slides in $70 \%$ glyicerol. The microscope analysis was done and the images obtained using Dewinter image microscope at 10X magnification.

\section{$3 \quad$ Results}

\section{$3.1 \quad$ W. somnifera}

The thickness of the lamina of s-UV-B treated leaves was found to be increased. A deposition of waxy layer was observed on the epidermis (light brown in color). The upper epidermis was also found to be darkened; even the lower epidermis in the curled/ cupped leaves was recorded to be dark in color (Fig.1). No obvious differences were obtained at the anatomical level in the roots of W. somnifera (Fig.2); morphologically, however, root girth was decreased in s-UV-B treated plants [18].

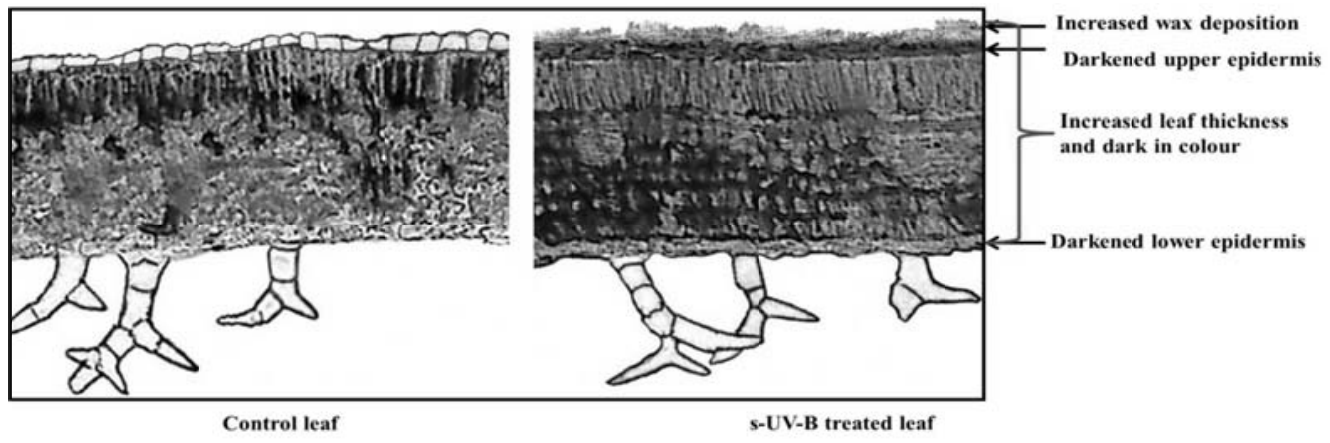

Figure 1. Transverse section of control and s-UV-B treated leaves of W. somnifera. Magnification=10X. 


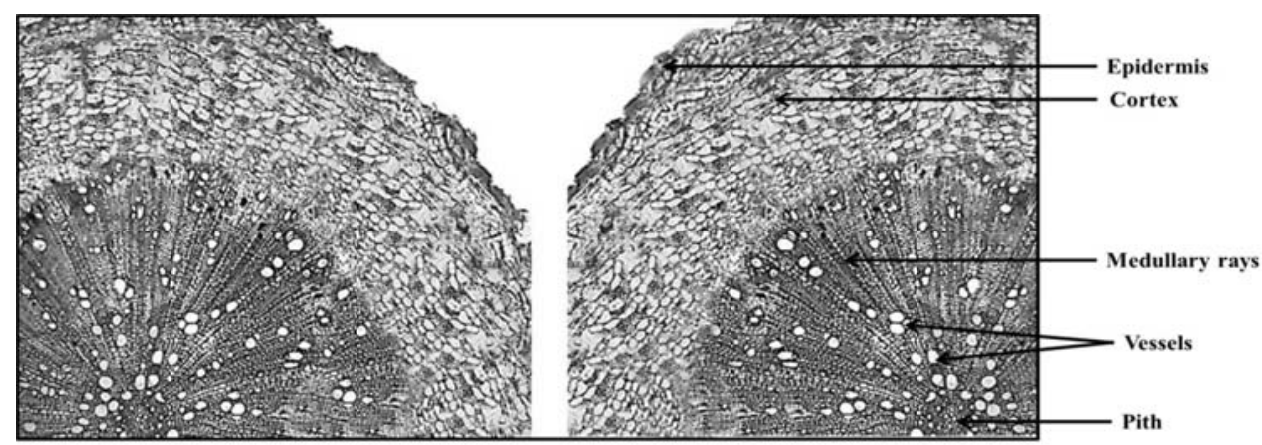

Figure 2. Transverse section of control and s-UV-B treated roots of W. somnifera. Magnification=10X.

\subsection{C. forskohlii}

Under s-UV-B, leaf thickness did not change in $C$. forskohlii. The major obvious differences observed in the leaves were the darkening of the epidermis, increased number of abaxial trichomes (increased trichome density), and light colored oil globules on the abaxial surface compared to the control ones (Fig.3). Roots of C. forskohlii showed significant differences even under this preliminary analysis upon sUV-B treatment. The epidermal layer was comparatively darkened and the cambial cell layer was reduced in thickness. However, from the economic and therapeutic point of wiew, the roots were negatively affected in that the number of cork cells (and cork cell layer thickness) which contain essential oil globules was found to be reduced, reducing the overall number of these globules; oil globules, however, increased in size (Fig.4).

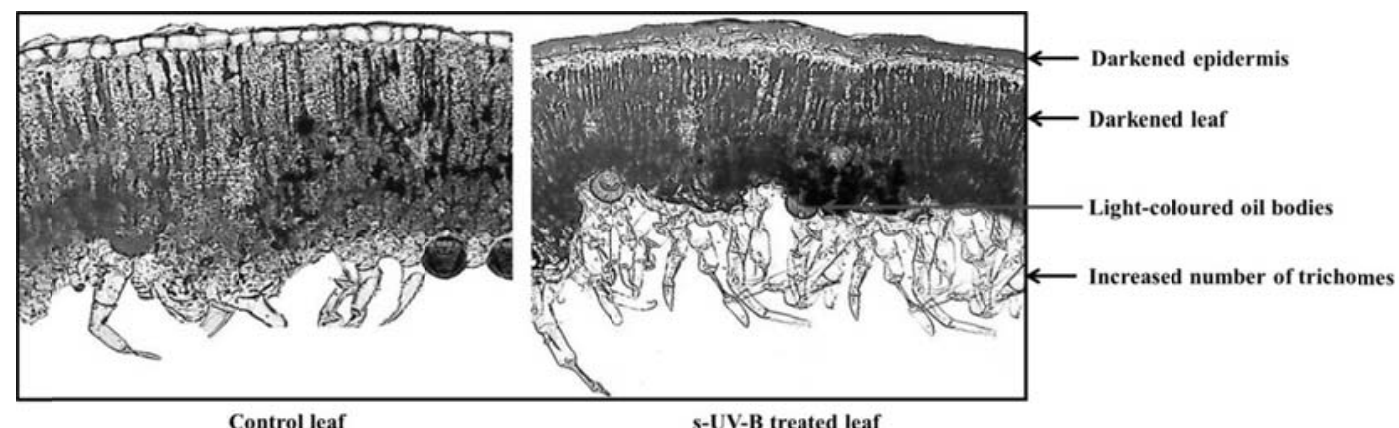

Figure 3. Transverse section of control and s-UV-B treated leaves of C. forskohlii. Magnification=10X.

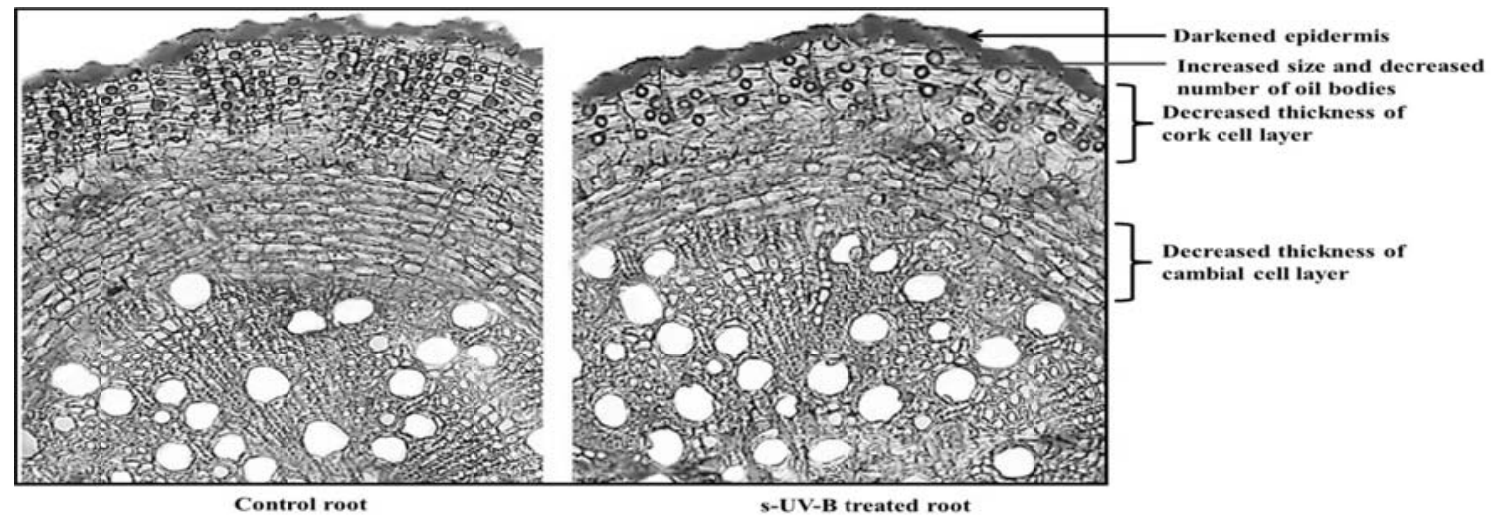

Figure 4. Transverse section of control and s-UV-B treated roots of C. forskohlii. Magnification=10X. 


\section{Discussion}

The increased leaf thickness of $W$. somnifera observed in the present study is corroborated by similar observations by Phoenix et al. [19] in Vaccinium myrtillus under elevated levels of UV-B. The probable reason may be due to the increased thickness of mesophyll tissue layer in the leaf. Recently, similar observations were recorded in the blueberry leaves with greater thickness being recorded in the younger leaves [20]. The increased leaf thickness can be considered a mechanism to resist penetration of excess UV-B. However, this strategy is not a conclusive evidence of plant resistance; rather, it is more in the nature of an adaptive response [21].

Similar to the results observed in W. somnifera leaves, increase in epicuticular wax content was previously reported in pea [22] and in cotton [23]. This enhancement may contribute towards reducing the amount of UV-B radiation penetrating internal leaf structures as well as increasing the reflectance of the incident UV-B $[24,25]$. SEM analysis of the medicinal plant Cymbopogon citratus also revealed a dense waxy covering on the adaxial surfaces which were exposed to s-UV-B [26].

The epidermis also contains UV-B absorbing compounds [27]. For instance, flavonoids are photostable and have a wide light absorption range $(220-380 \mathrm{~nm})$. They have been reported to be present in higher concentrations in both the leaf hair and the leaf epidermis [28]. Colored compounds such as anthocyanins, carotenoids, and some flavonoid groups serve as UV-screening pigments and their enhanced concentrations under s-UV-B are responsible for the darkened colour of the epidermis as well as leaves [29,30,31]. These compounds are also known to protect the photosynthetic apparatus from oxidative damage due to s-UV-B. The quantitative analysis of these compounds showed their enhanced concentrations in s-UV-B treated plant organs, both in leaves and roots [32,33].

Increased number of leaf trichomes (as observed on the abaxial surface of $C$. forskohlii leaves) under elevated UV-B levels has been reported previously [34]. They are epidermal leaf hairs which reduce water loss from the leaf surface via transpiration. When present on UV-B exposed surfaces, they may be equipped with UV-B absorbing compounds and may prove to be instrumental in preventing excessive UV-B radiation reaching the internal tissues [35].

Low levels of s-UV-B caused an increase in essential oil content in Ocimum sanctum. This was corroborated by SEM analysis which showed that partially filled oil sacs with wrinkled membranes in control plants were replaced by smooth and round oil sacs (with turgid membranes due to increased oil content in them) under s-UV-B [36]. Hand-cut sections of the leaf blades of C. citratus showed fully filled oil cells (more darkly stained) in treated plants compared to the control ones whence the oil cells were only partially filled [37]. However, in the present study, oil bodies were found to be light in color (indicating a reduction in essential oil content) in both leaves and roots of $C$. forskohlii. Anatomical changes in the roots of plants due to s-UV-B, to the best of our knowledge, are currently lacking, so it is not possible to compare our results with other studies. The reduced number of oil globules (and hence essential oil content) in root cork cells are corroborated by the quantitative analysis of oil via Clevenger apparatus. The average essential oil yield (volume of essential oil obtained in $1 \mathrm{~m}^{2}$ of plot area) for control plants was recorded to be $260 \mathrm{\mu l} \mathrm{m}^{-2}$ while it reduced significantly to $180 \mu \mathrm{m} \mathrm{m}^{-2}$ in s-UV-B treated plant roots.

\section{Conclusions and Future Perspectives}

The anatomical changes observed in the leaves of both the test plants and the roots of $C$. forskohlii reveal that s-UV-B is a potent factor in influencing the plants at the cellular level and the plants are also capable of defending themselves (at least partially) against this stress factor as evidenced by the increased thickness of waxy layer ( $W$. somnifera), increased concentration of UV-B screening compounds (darkened epidermis and darkened leaves in both plants, and epidermal layer of roots in C. forskohlii), and increased trichomes on the abaxial surface (C. forskohlii leaves). In the present study, s-UV-B proved to be detrimental as it lowered the essential oil content (especially in the roots) in $C$. forskohlii.

These observations, though significant, however, are insufficient to be conclusively correlated with the overall plant performance. Further studies using more sophisticated instruments and techniques such as microtomy, SEM, and TEM analysis will prove to be instrumental in furthering in-depth anatomical studies on the test plants and will be helpful in deriving more tangible results and conclusions. 
Acknowledgments. The authors are thankful to the Head, Department of Botany and Co-ordinator, Centre of Advanced Study in Botany, Banaras Hindu University, for providing laboratory facilities, and to the University Grants Commission (UGC), New Delhi, for financial assistance.

\section{References}

1. V. Shah, "Cultivation and utilization of medicinal plants (supplement)", RRL and CSIR, Jammu-Tawai, 1996, pp. 385-411.

2. C. A. Jaleel, R. Gopi, P. Manivannan, and R. Panneerselvam, "Exogenous application of triadimefon affects the antioxidant defense system of Withania somnifera Dunal.", Pesticide Biochemistry and Physiology, vol. 91, no. 3, pp. 170-174, 2008.

3. P.P. Joy, J. Thomas, S. Mathew, and B. P. Skaria, "Medicinal Plants" In Tropical Plants Vol.2, Naya Prokash, Calcutta, 2001, pp. 449-632.

4. N. Alam, M. Hossain, M. I. Khalil, M. Moniruzzaman, S. A. Sulaiman, and S. A. Gan, "Recent advances in elucidating the biological properties of Withania somnifera and its potential role in health benefits", Phytochemistry Reviews, vol. 11, pp. 97-112, 2012.

5. S. Sivamani, B. Joseph, and B. Kar, "Anti-inflammatory activity of Withania somnifera leaf extract in stainless steel implant induced inflammation in adult zebrafish", Journal of Genetic Engineering and Biotechnology, vol. 12, pp. 1-6, 2014.

6. S. K. Verma and A. Kumar, "Therapeutic uses of Withania somnifera (Ashwagandha) with a note on withanolides and its pharmacological actions", Asian Journal of Pharmaceutical and Clinical Research, vol. 4, no. 1, pp. 1-4, 2011.

7. V. Sharma, S. Sharma, and R. Paliwal, "Withania somnifera: A rejuvenating ayurvedic medicinal herb for the treatment of various human ailments", International Journal of PharmTech Research, vol. 3, no. 1, pp. 187-192, 2011.

8. I. Pateraki, J. Andersen-Ranberg, A. M. Heskes, H. J. Martens, P. Zerbe, S. S. Bach, B. L. Møller, J. Bohlmann, and B. Hamberger, "Manoyl oxide (13R), the biosynthetic precursor of forskolin, is synthesized in specialized root cork cells in Coleus forskohlii", Plant Physiology, vol. 164, pp. 1222-1236, 2014.

9. S. Kamohara, and S. Noparatanawong, "A Coleus forskohlii extract improves body composition in healthy volunteers: An open-label trial", Personalized Medicine Universe, vol. 2, pp. 25-27, 2013.

10.H. N. Shivaprasad, S. Gopalakrishna, B. Mariyanna, M. Thekkoot, R. Reddy, and B. S. Tippeswamy, "Effect of Coleus forskohlii extract on cafeteria diet-induced obesity in rats", Pharmacognosy Research, vol. 6, no. 1, pp. 42-45, 2014.

11.M. Paul, A. Radha, and D. S. Kumar, "On the high value medicinal plant, Coleus forskohlii Briq.", Hygeia:: Journal for Drugs and Medicines, vol. 5, no. 1, pp. 69-78, 2013.

12.R. L. McKenzie, P. J. Aucamp, A. F. Bais, L. O. Björn, M. Ilyas, and S. Madronich, "Ozone depletion and climate change: impacts on UV radiation", Photochemical and Photobiological Sciences, vol. 10, pp. 182-198, 2011.

13.C. L. Ballaré, M. M. Caldwell, S. D. Flint, A. A. Robinson, and J. F. Bornman, "Effects of solar ultraviolet radiation on terrestrial ecosystems. Patterns, mechanisms, and interactions with climate change", Photochemical and Photobioogical Sciences, vol. 10, pp. 226-241, 2011.

14.J. G. Anderson, D. M. Wilmouth, J. B. Smith, and D. S. Sayers, "UV dosage levels in summer: Increased risk of ozone loss from convectively injected water vapour", Science, vol. 337, pp. 835-839, 2012.

15.J. C. Laube, M. J. Newland, C. Hogan, C. A. M. Brenninkmeijer, P. J. Fraser, P. Martineire, D. E. Oram, C. E. Reeves, T. Röckmann, J. Schwander, E. Witrant, and W. T. Sturges, "Newly detected ozone depleting substances in the atmosphere", Nature Geoscience, vol. 7, pp. 266-269, 2014.

16.F. Hollósy, "Effects of ultraviolet radiation on plant cells", Micron, vol. 33, pp. 179-197, 2002.

17.M. M. Caldwell, "Solar ultraviolet radiation and the growth and development of higher plants" In Phytophysiology, Academic Press, New York, 1971, pp. 131-177. 
18.S. Takshak, and S. B. Agrawal, "Effect of ultraviolet-B radiation on biomass production, lipid peroxidation, reactive oxygen species, and antioxidants in Withania somnifera", Biologia Plantarum, vol. 58, no. 2, pp. 328-334, 2014.

19.G. K. Phoenix, D. Gwynn-Jones, T. V. Callaghan, D. Sleep, and J. A. Lee, "Effects of global change on a subarctic heath: effects of enhanced UV-B radiation and increased summer precipitation", Journal of Ecology, vol. 89, no. 2, pp. 256-267, 2001.

20.M. Reyes-Díaz, C. Meriño-Gergichevich, C. Inostroza-Blancheteau, M. Latsague, P. Acevedo, and M. Alberdi, "Anatomical, physiological, and biochemical traits involved in the UV-B radiation response in highbush blueberry", Biologia Plantarum, vol. 60, no. 2, pp. 355-366, 2016.

21.V. G. Kakani, K. R. Reddy, D. Zhao, and K. Sailaja, "Field crop responses to ultraviolet-B radiation: a review", Agricultural and Forest Meteorology, vol. 120, pp. 191-218, 2003.

22.J. E. Corlett, J. Stephen, H. G. Jones, R. Woodfin, R. Mepsted, and N.D. Paul, "Assessing the impact of UV-B radiation on the growth and yield of field crops" In Plants and UV-B: responses to environmental change, Society for Experimental Biology, Seminar Series 64. Cambridge University Press, Cambridge, 1997, pp. 195-211.

23.V. G. Kakani, K. R. Reddy, D. Zhao, and A. R. Mohammed, "Effects of ultraviolet-B radiation on cotton (Gossypium hirsutum L.) morphology and anatomy", Annals of Botany, vol. 91, pp. 817-826, 2003.

24.M. Tevini, and D. Steinmüller, "Influence of light, UV-B radiation, and herbicides on wax biosynthesis of cucumber seedlings", Journal of Plant Physiology, vol. 131, pp. 111-121, 1987.

25.M. G. Holmes, "Action spectra for UV-B effects on plants: monochromatic approaches for analyzing plant responses" In Plants and UV-B: responses to environmental change, Society for Experimental Biology, Seminar Series 64. Cambridge University Press, Cambridge, 1997, pp. 31-50.

26.R. Kumari, and S. B. Agrawal, "Supplemental UV-B induced changes in leaf morphology, physiology, and secondary metabolites of an Indian aromatic plant Cymbopogon citratus (D.C.) Staph under natural field conditions", International Journal of Environmental Studies, vol. 67, no. 5, pp. 655-675, 2010.

27.H. Skaltsa, E. Verykokidon, C. Harvala, G. Karabourniotis, and Y. Manetas, "UV-B protective potential and flavonoid content of leaf hairs of Quercus ilex", Phytochemistry, vol. 37, no. 4, pp. 987-990, 1994.

28.J.B. Harborne, "Nature, distribution and function of plant flavonoids", Progress in Clinical and Biological Research, vol. 213, pp. 14-24, 1986.

29.L. C. Olsson, M. Veit, and J.F. Borman, "Epidermal transmittance and phenolic composition in leaves of atrazine-tolerant and atrazine-sensitive cultivars of Brassica napus grown under enhanced UV-B radiation", Physiologia Plantarum, vol. 107, no. 3, pp. 259-266, 1999.

30.E.H. Middleton, and A.H. Teramura, "The role of flavonol glycosides and carotenoids in protecting soy bean from ultraviolet- B damage", Plant Physiology, vol. 103, no. 3, pp. 741-752, 1993.

31.M. A. K. Jansen, V. Gaba, and B. M. Greenberg, "Higher plants and UV-B radiation: Balancing damage, repair and acclimation", Trends in Plant Science, vol. 3, no. 4, pp. 131-135, 1998.

32.S. Takshak, and S. B. Agrawal, "Secondary metabolites and phenylpropanoid pathway enzymes as influenced under supplemental ultraviolet-B radiation in Withania somnifera Dunal, an indigenous medicinal plant", Journal of Photochemistry and Photobiology B: Biology, vol. 140, pp. 332-343, 2014.

33.S. Takshak, and S. B. Agrawal, "Defence strategies adopted by the medicinal plant Coleus forskohlii against supplemental ultraviolet-B radiation: Augmentation of secondary metabolites and antioxidants", Plant Physiology and Biochemistry, vol. 97, pp. 124-138, 2015.

34.P. W. Barnes, C. L. Ballaré, and M. M. Caldwell, "Photomorphogenic effects of UV-B radiation on plants: consequences for light competition", Journal of Plant Physiology, vol. 148, pp. 15-20, 1996.

35.G. Karabourniotis, K. Papadopoulos, M. Papamarkou, and Y. Manetas, "Ultraviolet-B radiation absorbing capacity of leaf hairs", Physiologia Plantarum, vol. 86, no. 3, pp. 414-418, 1992.

36.R. Kumari, and S. B. Agrawal, "Comparative analysis of essential oil composition and oil containing glands in Ocimum sanctum L. (Holy basil) under ambient and supplemental level of UV-B through gas chromatographymass spectrometry and scanning electron microscopy", Acta Physiologiae Plantarum, vol. 33, no. 4, pp. 1093$1101,2011$.

37.R. Kumari, S. B. Agrawal, and A. Sarkar, "Evaluation of changes in oil cells and composition of essential oil in lemongrass (Cymbopogon citratus (D.C.) Stapf.) due to supplemental ultraviolet-B irradiation", Current Science, vol. 97, no. 8, pp. 1137-1142, 2009. 